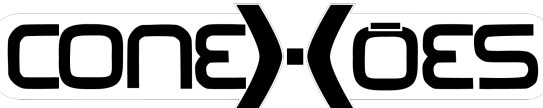

CIÊNCIA E TECNOLOGIA

\section{A INSERÇÃO DA HISTÓRIA E FILOSOFIA DA CIÊNCIA NO ENSINO DE CIÊNCIAS: UMA VISÃO GERAL A PARTIR DA ANALISE DE ARTIGOS DISPONÍVEIS NO PORTAL DE PERIÓDICOS DA CAPES}

\author{
Ronaldo Coelho Pereira, Haroldo Reis Alves de Macêdo, Inaiara Leite Rodrigues ${ }^{1}$ \\ ${ }^{1}$ Instituto Federal do Piauí - Campus Picos \\ <ronaldocoelho18@gmail.com>,<haroldoram@ifpi.edu.br>,<inaiaraleite68@gmail.com>
}

DOI: https://doi.org/10.21439/conexoes.v13i4.1865

\begin{abstract}
Resumo. As pesquisas no campo de didática apontam para um consenso quanto aos benefícios da inserção da História e Filosofia da Educação no ensino de ciências. Há uma forte defesa que a abordagem histórico-filosófica possa contribuir para o aprendizado de conceitos e alteração das percepções distorcidas de ciência nutridas a partir das abordagens tradicionais, isso, pois em contraponto a abordagem tradicional, as estratégias usando a HFC apresentam a ciência como algo de caráter evolutivo e como um componente da cultura humana que influencia e é influenciado por aspectos históricos, sociais e culturais. Partindo dessa perspectiva, o trabalho tem por objetivo esboçar um panorama geral da inserção da HFC no ensino através de uma pesquisa qualitativa feita com uma amostra de 10 artigos disponíveis no portal "Periódicos CAPES". Através da análise dos trabalhos pôde-se constatar uma diversidade de abordagens para o tema, as principais são: reflexões sobre a inserção e importância da HFC no ensino de ciência; investigações sobre as percepções de professores e alunos sobre o tema; análises documentais de publicações na área e de documentos institucionais e a aplicações de estratégias didáticas usando da HFC em sala. A existência dessas abordagens em diferentes vertentes permitiu mapear os pontos positivos, limitações e as principais dificuldades apresentadas nos trabalhos para a inserção da HFC no ensino de ciência.
\end{abstract}

Palavras-chaves: História e Filosofia da Ciência, inserção, ensino e artigos.

\begin{abstract}
Research in the field of didactics points to a consensus about the benefits of the insertion of History and Philosophy of Science in science teaching. There is a strong defense that the historicalphilosophical approach can contribute to the learning of concepts and alteration of distorted perceptions of science nurtured from traditional approaches, this, because in counterpoint the traditional approach, HFC strategies present science as evolutionary and as a component of human culture that influences and is influenced by historical, social, and cultural aspects. From this perspective, the objective of this work is to outline an overview of the HFC insertion in teaching through a qualitative research done with a sample of 10 articles available on the "Periódicos CAPES" portal. Through the analysis of the work it was possible to verify a diversity of approaches to the theme, the main ones are: reflections about the insertion and importance of HFC in science teaching; investigations about the perceptions of teachers and students on the subject; documentary analyzes of publications in the area and institutional documents and the application of didactic strategies using HFC in the classroom. The existence of these approaches in different aspects allowed to map the positive points, limitations and main difficulties presented in the works for the insertion of HFC in science teaching.
\end{abstract}

Keywords: History and Philosophy of Science, insertion, teaching and academic articles. 


\section{INTRODUÇÃO}

$\mathrm{Na}$ área de ensino em ciências, em geral, e de ensino em física, em particular, tem se discutido a inserção de aspectos referentes à História e Filosofia da Ciência (HFC). As principais pesquisas e posições de especialistas que estudam a HFC na perspectiva do ensino convergem para um consenso quanto aos benefícios da inserção da HFC para o ensino e aprendizagem.

Em muitas situações apenas uma abordagem simplificada (isto é, uma abordagem meramente conceitual e/ou matematizada, sem estabelecer relações com a realidade e discutir a relevância do estudado) é um fator limitante para o aprendizado de tópicos de ciências. Nesse aspecto a HFC é cogitada como um dos artifícios didáticos que podem atenuar esse problema, pois uma abordagem à luz da história e filosofia da ciência possibilita a contextualização dos sabres e conferem aos conteúdos, conceitos e ideias trabalhados pelos professores(as) a noção de algo em vivo, em movimento ao longo da história, aproximando-os de aspectos da vida humana (PENITENTE; CASTRO, 2011).

Nessa perspectiva de defesa da HFC no ensino, (MOURA, 2014) aponta que a HFC possui um potencial pedagógico extremamente favorável ao docente que tenha por ambição alcançar melhores resultados no ensino de ciência. A sua inserção no ensino possibilita a construção de diversas estratégias didáticas com práticas pedagógicas diferentes, por exemplo: leitura e construção de textos históricos, peças teatrais, debates, reprodução de experimentos históricos, entre outras.

Um reflexo do consenso quanto à inserção da HFC no ensino são as orientações expressas nos principais documentos que norteiam a educação nacional, como nas Diretrizes Curriculares para o Ensino de Física, Química e Biologia e os Parâmetros Curriculares Nacionais (PCN's) e Orientações Curriculares para o Ensino Médio, onde se recomenda a inserção de conteúdos de natureza histórico-filosófica.

Nos PCN's para o Ensino Médio pode-se observar essas recomendações no tópico Conhecimentos em Física no documento Parte III - Ciências da Natureza e suas Tecnologias, onde se menciona:

Compreender a construção do conhecimento físico como um processo histórico, em estreita relação com as condições sociais, políticas e econômicas de uma determinada época. [...] Compreender a Física como parte integrante da cultura contemporânea, identificando sua presença em diferentes âmbitos e setores [...]. Reconhecer, em situações concretas, a relação entre Física e ética, seja na definição de procedimentos para a melhoria das condições de vida, seja em questões como do desarmamento nuclear ou em mobilizações pela paz mundial (BRASIL 1999.
Partindo dessa perspectiva o presente trabalho tem como objetivos, num primeiro momento, expor uma visão geral do que é HFC e Natureza da Ciência (NdC). Em seguida apresentar um levantamento dos artigos publicados no período de 2010 a 2018 disponíveis no Portal Periódicos CAPES que abordem a HFC. Bem como expor a análise de uma amostra destes artigos traçando uma visão geral de como o tema é trabalhado, como ele está inserido no ensino, quais as problemáticas em torno da sua inserção, limitações e melhorias apontadas no ensino a partir da sua inserção.

A fonte motivadora para o desenvolvimento da pesquisa foram discussões promovidas na disciplina de Metodologia do Ensino de Física do curso de Licenciatura em Física do IFPI - Campus Picos, que dentre os diversos tópicos abordados, discutiu o uso da HFC como estratégia metodológica no ensino de ciências. A partir do contato com a temática surgiu como questão "conhecer os aspectos atuais da inserção da HFC no ensino de ciência" culminando em uma investigação documental qualitativa de artigos abordando a inserção da HFC no ensino de ciência, onde se procedeu metodologicamente observando aspectos da análise de conteúdo descrita por Bardin (2011).

\subsection{Natureza da Ciência e História e Filosofia da Ciência no Ensino}

A NdC compreende a investigação da gênese do conhecimento científico, propõe a investigação e reflexão do que é ciência, como se dá o processo de compreensão do mundo natural e como os aspectos históricos, sociais e culturais exercem influência sobre esse processo. Para se entender a evolução das ideias e teorias cientificas é essencial começar pela natureza da ciência.

\footnotetext{
A natureza da Ciência é entendida como um conjunto de elementos que tratam da construção, estabelecimento e organização do conhecimento científico. Isto pode abranger desde questões internas, tais como método científico e relação entre experimento e teoria, até outras externas, como a influência de elementos sociais, culturais, religiosos e políticos na aceitação ou rejeição de ideias científicas (MOURA 2014 p. 32).
}

Segund Bezerra (2014) a melhor maneira de entender a NdC é primeiro pensar sobre a alfabetização científica, visto que este é o principal objetivo da educação em ciências. Essa alfabetização se refere à aquisição de competências por parte do indivíduo, capazes de fazêlo: compreender tópicos sobre ciência presentes na cultura pop; reconhecer e valorizar as contribuições cientifica; usar a ciência para fazer escolhas tanto no cotidiano como em questões sociais e científicas, ou seja, 
A INSERÇÃO DA HISTÓRIA E FILOSOFIA DA CIÊNCIA NO ENSINO DE CIÊNCIAS: UMA VISÃO GERAL A PARTIR DA ANALISE DE ARTIGOS DISPONÍVEIS NO PORTAL DE PERIÓDICOS DA CAPES

desenvolver no sujeito a capacidade do mesmo pensar cientificamente.

A abordagem da $\mathrm{NdC}$ majoritariamente se vale da implementação da HFC no ensino, uma vez que esta, seja enquanto disciplina ou estratégia didática, agrega ao conteúdo/conceito estudado uma dimensão histórica, social e cultural, corroborando assim para reflexões presentes no arcabouço da $\mathrm{NdC}$.

A inserção da HFC no ensino de ciência se apresenta como uma das estratégias de ensino alternativa às metodologias puramente tradicionais apontadas nas pesquisas em ensino de ciências como incapazes de promover uma efetiva alfabetização científica, constatação que se evidencia analisando os indicadores nacionais e internacionais da educação básica, como o Programa Internacional de Avaliação de Estudantes (PISA) de 2018 onde o país no ranking de proficiência com outros 69 países ficou em $64^{\circ}$ em ciências e apresentou como resultado que 56,6\% dos estudantes brasileiros com até 15 estão abaixo do nível básico de proficiência na área.

Para Silva (2010) a HFC pode contribuir para uma melhor compreensão de diversos aspectos relativos à Natureza da Ciência, como a relação ciência-sociedade, a percepção da ciência como atividade humana, a falibilidade das teorias cientistas, entre outros, como também pode propiciar um melhor aprendizado dos próprios conceitos científicos.

Seguindo essa linha de pensamento, Raposo (2014 argumenta que para os futuros professores o estudo de HFC e da NdC, além de aumentar em muito a sua compreensão da ciência, pode mostrar como a sociedade, o contexto histórico e os interesses econômicos e políticos podem influenciar no trabalho da Ciência. Dessa forma, consequentemente contribuindo para a construção de aulas mais contextualizadas e significativas.

Apesar das discussões e pesquisas no Brasil sobre a introdução da HFC serem relativamente recentes, no exterior essa inserção já era discutida e fomentada há décadas por especialistas e instituições. Um exemplo notável foi o projeto educacional desenvolvido pela National Science Foundation com a Universidade de Harvard e implementado nos EUA entre os anos de 1962 e 1970, cujo nome original é Project Physics Course. Este se destinava ao ensino básico, mas acabou ganhando a adesão em universidades nas disciplinas introdutórias de cursos de ciência, o mesmo era fundamentado em princípios históricos, componente humanístico e preocupado com as dimensões culturais e filosóficas da ciência, e desenvolvido a partir da colaboração de historiadores e filósofos da ciência, físicos, astrônomos, químicos, educadores de ciências, psicólogos, especi- alistas de avaliação, dentre outros profissionais (SAUERWEIN; DELIZOICOV, 2008).

Anterior a isso, o prêmio Nobel de Física, de 1944, Isidor Isaac Rabi, já defendia uma abordagem científica através do uso da HFC. Isso pode ser observado em uma de suas falas na introdução do Harvard Physics Project:

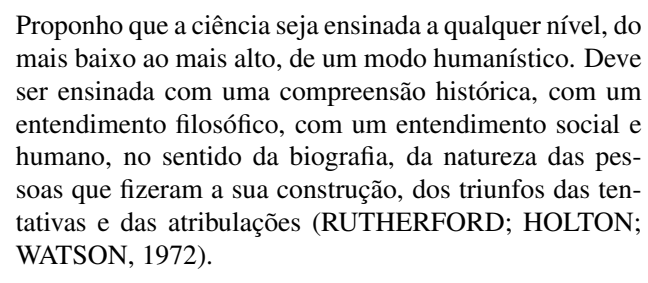

Proponho que a ciência seja ensinada a qualquer nível, do mais baixo ao mais alto, de um modo humanístico. Deve ser ensinada com uma compreensão histórica, com um entendimento filosófico, com um entendimento social e humano, no sentido da biografia, da natureza das pessoas que fizeram a sua construção, dos triunfos das tentativas e das atribulações (RUTHERFORD; HOLTON; WATSON 1972.

\section{METODOLOGIA}

O desenvolvimento desta pesquisa consistiu predominantemente na análise de conteúdo de artigos disponíveis no portal de periódicos da Coordenação de Aperfeiçoamento de Pessoal de Nível Superior (CAPES) publicados no período de 2010 a 2018, a escolha da década vigente como intervalo de tempo deu-se visando a obtenção de um retrato atual do tema investigado.

A análise de conteúdo é definida por Bardin (2011) como um método empírico, formado por um conjunto de instrumentos de cunho metodológico em constante aperfeiçoamento, que se aplica a discursos e conteúdos extremamente diversificados tendo como função primordial o desvendar crítico. As principais características da análise de conteúdo em Bardin (2011) são o foco na mensagem dos documentos e a agregação destes em categorias temáticas a partir da análise de seus conteúdos objetivando-se confirmar indicadores que permitam, de forma crítica, inferências sobre outra realidade que não a da mensagem especifica de cada documento, mas geralmente de uma questão mais ampla (SANTOS, 2012).

A presente pesquisa tem caráter qualitativo, pois a coleta de dados se deu pela investigação de conteúdo de produções escritas, e a análise de conteúdo norteou-se pela descrição de Bardin (2011). Para tal, incialmente foi feito um levantamento no portal de periódicos através do seu mecanismo de busca de trabalhos que oferece diversas opções e combinações de filtros. Para o levantamento dos artigos que abordam a HFC foi usado como filtro à combinação "Contém: História e Filosofia da Ciência/Artigos/2010-2018”, para essa combinação apareceram cerca 5.597 resultados. Após se alterar o filtro para "Contém no Título: História e Filosofia da Ciência/Artigos/2010-2018" apareceram 47 resultados. Essa diferença se justifica devido à no primeiro filtro os resultados incluírem qualquer artigo que mencione 

DE ARTIGOS DISPONÍVEIS NO PORTAL DE PERIÓDICOS DA CAPES

"História e Filosofia da Ciência" em algum trecho do texto, enquanto no segundo filtro necessariamente devia constar no título, assegurando assim que o artigo abordasse como tema central a HFC.

Inicialmente foi feito uma pré-análise dos 47 trabalhos presentes nos resultados da busca, que consistiu na leitura de seus respectivos resumos. Em seguida, excluiu-se os que não abordavam a HFC na vertente da inserção no ensino e delimitou -se a amostra a 10 artigos de forma que abarcassem diferentes abordagens quanto ao objeto de pesquisa. Durante a análise de conteúdo os artigos foram agrupados por grau de semelhança na abordagem, algo próximo à ideia de categorias temáticas. A distribuição dos artigos deu-se nos seguintes grupos: o uso da HFC como estratégias didáticas (03 artigos), a inserção da HFC na formação de professores (03 artigos), discussões/reflexões sobre a importância da HFC no ensino de ciências (02), investigação sobre as percepções de licenciandos sobre a inserção da HFC no Ensino Médio (01 artigos) e investigação documental qualitativa quanto à presença da HFC nas matrizes curriculares de cursos de Licenciatura em física (01).

\section{RESULTADOS}

A amostra selecionada para a pesquisa, isto é, os 10 artigos selecionados a partir da busca no portal de periódicos, encontram-se dispostos na tabela abaixo. Em função da extensão dos títulos é inviável citá-los no decorrer deste trabalho com suas respectivas denominações, para tal eles serão mencionados ao longo do trabalho como A1, A2, A3, e assim sucessivamente até o A10. As citações diretas presentes nas discussões que se seguem estão relacionadas cada uma respectivamente ao artigo citado, cujo autor figura na citação indireta e na Tabela??

Os artigos A01, A02 e A03 trabalham a HFC como estratégias didáticas através da elaboração e desenvolvimento de sequências didáticas que tragam uma abordagem histórico-filosófica do conteúdo estudado. Duas sequencias foram executadas na disciplina de Física no Ensino Médio (A01 e A03) e uma na disciplina de Introdução a Mecânica em duas turmas de graduação, uma do curso de Licenciatura em Física e outra de Bacharelado em Geofísica (A02). Apesar de cada trabalho ter desenvolvido a estratégia de forma própria, pode-se notar semelhanças entre eles principalmente entre o artigo A01 e A02 onde ambos possuem como objetivo avaliar a inserção de uma estratégia didática usando da HFC.

Dentre os aspectos comuns das pesquisas desenvolvidas em A01 e A02 estão: a aplicação de um questionário inicial aos alunos para investigar suas concep- ções individuais sobre o assunto abordado na sequência e se elas estão de acordo com a concepção física ou se tratam de concepções alternativas presentes no desenvolvimento histórico daquele conceito/teoria; o uso de textos históricos abordando o desenvolvimento histórico do tópico trabalhado; discursões em sala entre os alunos com a mediação do professor; registros das percepções dos alunos quanto à metodologia usada e avaliação da apreensão por parte dos alunos dos conceitos trabalhados através de questionários e/ou produção textual.

O trabalho de pesquisa do artigo A03 teve como aspectos do seu desenvolvimento: uma abordagem histórica exposta pelo professor que buscou caracterizar o contexto sociocultural e os eventos históricos do período em que se desenvolveu o conceito trabalhado e suas posteriores revisões; a utilização de materiais audiovisuais como vídeos, slides, imagens históricas de laboratórios, experimentos, máquinas e cenários, animações; discursões em sala mediadas pelo professor; apresentação parcial das biografias dos cientistas que contribuíram para o desenvolvimento do conceito; leitura de um texto interdisciplinar abordando a relação ciência-sociedade a partir do tópico discutido; avaliação do projeto através de uma produção textual em determinado ponto da sequência sobre o conceito discutido e uma entrevista com os estudantes ao final desta para registro das percepções quanto à metodologia usada.

A confecção e execução das sequências didáticas apresentadas nos três artigos usando a HFC como estratégia de ensino rompe com as metodologias tradicionais de ensino de ciências e possibilitam uma percepção da ciência como um empreendimento coletivo e indissociavelmente atrelada a fatores sociais, históricos e culturais, onde estes influenciam no seu desenvolvimento e vice versa. Além de contribuir para a desconstrução do estereotípico equivocado do cientista (gênio, alguém que nunca erra, ocupação para seletas pessoas e equivalentes).

As conclusões dos três trabalhos com base na analise dos dados colhidos apontam para resultados positivos quando a inserção da HFC como estratégia didática: no artigo A01 encontra-se:

\footnotetext{
De forma geral, observou-se que a estratégia didática favoreceu a humanização do ambiente escolar, o trabalho em grupo, o diálogo entre os estudantes, a socialização das concepções alternativas referentes aos assuntos estudados, inclusive identificando semelhanças com visões históricas, a problematização de questões relativas à Natureza da Ciência, a argumentação, o trabalho com hipóteses, a comunicação em Física e, por fim, a aprendizagem de conceitos e temas científicos (SILVA 2011a p. 11).
} 


\begin{tabular}{|c|l|l|l|}
\hline Artigo & Ano & \multicolumn{1}{|c|}{ Autor(es) } & \multicolumn{1}{c|}{ Título } \\
\hline A01 & 2012 & Silva, B. V. da C. & $\begin{array}{l}\text { História e Filosofia da Ciência como subsídio } \\
\text { para elaborar estratégias Didáticas em Sala de Aula: } \\
\text { um relato de experiência em sala de aula }\end{array}$ \\
\hline A02 & 2015 & Monteiro, M. M; Martins, A. F. P. & $\begin{array}{l}\text { História da Ciência na sala de aula: uma sequência } \\
\text { didática sobre o conceito de inércia }\end{array}$ \\
\hline A03 & 2013 & Morais, A; Guerra, A. & $\begin{array}{l}\text { História e a Filosofia da Ciência: caminhos para } \\
\text { a inserção de temas física moderna no estudo de } \\
\text { energia na primeira série do Ensino Médio }\end{array}$ \\
\hline A04 & 2015 & Oliveira, W. C. de; Drummond, J. M. H. F. & $\begin{array}{l}\text { Refletindo sobre desafios à inserção didática da } \\
\text { História e Filosofia da Ciência em oficina de } \\
\text { formação docente }\end{array}$ \\
\hline A05 & 2011 & Ataide, M. C. E. S; Silva, B. V. C. & $\begin{array}{l}\text { As metodologias de ensino de ciências: } \\
\text { contribuições da experimentação e da História } \\
\text { e Filosofia da Ciência }\end{array}$ \\
\hline A06 & 2011 & Silva, B. V. C. & $\begin{array}{l}\text { A História e a Filosofia da Ciência no no } \\
\text { Ensino Médio: a visão dos futuros professores } \\
\text { de física }\end{array}$ \\
\hline A07 & 2015 & Londero, L. & $\begin{array}{l}\text { A História e Filosofia da Ciência na formação } \\
\text { de professores de física: controvérsias curriculares }\end{array}$ \\
\hline A08 & 2012 & Almeida, M. J. P. M. de & $\begin{array}{l}\text { Leituras de História e Filosofia da Ciência na } \\
\text { formação inicial de professores }\end{array}$ \\
\hline A09 & 2017 & Melo, A P de; Rocha, D. C. & $\begin{array}{l}\text { Reflexões sobre a importância da História e } \\
\text { Filosofia da Ciência no Ensino de Ciências }\end{array}$ \\
\hline A10 & 2010 & Penitente, L. A. de A. & $\begin{array}{l}\text { A História e Filosofia da Ciência: contribuições } \\
\text { para o ensino de ciências e para a formação de } \\
\text { professores }\end{array}$ \\
\hline
\end{tabular}

No artigo A02:

Consideramos que, no particular contexto da pesquisa aqui relatada, a HFC parece haver contribuído para a compreensão do conceito de inércia por parte desses sujeitos [...]. Esse pode ser considerado um resultado importante, na medida em que nem todos os trabalhos que defendem o uso da HFC como estratégia didática sinalizam para a possibilidade (e importância) de física via HFC (MONTEIRO; MARTINS 2015. p. 4501-7).

O artigo A03 também faz menção aos aspectos positivos:

[...] percebemos que a sequencia didática ou elementos deste trabalho gerou reflexão e discussão sobre o conteúdo. Além disso, a análise dos instrumentos usados a fim de avaliar todo o processo evidenciou que, após o curso, os alunos reconheceram o conceito de energia como o conceito abrangente que é, bem como demonstraram uma visão menos ingênua da ciência no que diz respeito à sua construção. Logo, de uma forma geral, o projeto levou-nos a resultados positivos se considerarmos que uma relação didática terá sucesso se modicar as relações com os saberes que os alunos tinham antes dela [...] (MORAIS e GUERRA, p. 1502-9, 2013).
Apesar dos resultados positivos quanto à implantação da HFC como estratégia didática, os trabalhos também versam sobre as problemáticas e limitações de se trabalhar com o tema. Isso pode ser percebido no artigo A02:

No que diz respeito à aplicação da sequência didática como um todo, o tempo foi um dos nossos maiores empecilhos, tanto no que se refere ás discussões históricas dos textos, quanto, sobretudo, às discussões especificas sobre os conteúdos de NdC. Outra dificuldade foi a falta de hábito de leitura dos alunos, o que levava a erros de interpretação dos textos (MONTEIRO; MARTINS, 2015. p. 4501-6).

Como também é clara a cautela do autor do trabalho A02 quanto a não generalização dos resultados de uma aplicação especifica para demais contextos ou para todos os contextos educacionais:

Também devemos estar atentos às limitações de uma análise quantitativa e da utilização de questionários do tipo "antes e depois". Nesse sentido, a amostra estudada não permite generalizarmos esse resultado, dada a complexidade de fatores que influenciam o aprendizado em sala 
A INSERÇÃO DA HISTÓRIA E FILOSOFIA DA CIÊNCIA NO ENSINO DE CIÊNCIAS: UMA VISÃO GERAL A PARTIR DA ANALISE DE ARTIGOS DISPONÍVEIS NO PORTAL DE PERIÓDICOS DA CAPES

de aula e que estiveram em ação durante a aplicação da sequência (MONTEIRO; MARTINS 2015 p. 4501-7).

A inserção da HFC na formação de professores é discutida nos artigos A04, A08 e A10. No trabalho A10 é feita uma reflexão da importância da HFC para a formação de professores, tal reflexão se dá pela discussão das diferentes percepções de autores no que tange a importância desses saberes e o planejamento em ensino de ciência para a abordagem dessa temática em sala de aula. Já os artigos A04 e A08 descrevem o processo de inserção da HFC e seus desdobramentos através, respectivamente, da oferta de uma oficina como tema "Ensinando sobre a Natureza da Ciência: uma abordagem explícita e contextualizada a partir da História do Vácuo" para licenciandos e professores de Física do ensino básico e da leitura de textos de NdC e HFC numa disciplina de primeiro período de um curso de Licenciatura em Física.

A Reflexão trazida pelo trabalho A10 aponta para as possiblidades e potencialidades em se trabalhar os conteúdos por meio de uma dimensão histórico-filosófica suscitando também as mudanças nas relações sujeitoconhecimento, ensino-aprendizagem e aluno-professor:

\begin{abstract}
Reconhecer que o processo de construção do saber científico não é algo simples e banal já abre as possibilidades de reconstrução deste pelo (a) aluno (a); é claro, com a mediação do (a) professor (a). Isso implica em corroborarmos com as afirmações feitas de que o conhecimento científico é um produto da atividade humana e, embora essa construção do conhecimento apresente dificuldades e limitações, ela permite a participação de todos, como agentes ativos. Talvez, essa seja a maior contribuição que a abordagem histórica e filosófica da ciência pode propiciar aos educadores e educadoras (PENITENTE; CASTRO 2011 p. 243).
\end{abstract}

A pesquisa presente no artigo A04 se desenvolveu tendo como principais aspectos: a oferta de uma oficina com referencial teórico abordando a NdC e HFC; a delimitação de pré-requisitos para a elaboração de propostas didáticas para se trabalhar a temática no ensino; a elaboração em grupo de estratégias didáticas e materiais para se trabalhar em sala; socialização por parte dos participantes das estratégias criadas; avaliação da compatibilidade das propostas apresentadas pelos grupos com o exigido nos pré-requisitos apresentados; avaliação qualitativa do desenvolvimento do projeto e das percepções dos participantes a partir das observações e dados colhidos no decorrer da oficina.

Um dos aspectos mais frisados pelo autor no trabalho A04 são as dificuldades em se desenvolver estratégias para se trabalhar a $\mathrm{NdC}$ e HFC, no entanto o mesmo enfatiza que tais dificuldades não foram um fator limitante para o desenvolvimento destas ou desmotivação dos participantes:

\begin{abstract}
Notaram-se aspectos significativos quanto ao empenho e criatividade dos participantes. Foram citadas sugestões, como a criação de jornal histórico e elaboração de cena teatral, que poderiam resultar em atividades pedagogicamente adequadas. Analogia interessante trouxe à tona filme comercial em colaboração à compreensão de conteúdo histórico complexo. [...] Demonstrando significativo interesse, os participantes sugeriram ou mesmo chegaram a se empenhar em tentativas de elaboração de materiais didáticos do tipo narrativa histórica. Contudo, nesse processo, dificuldades significativas puderam ser notadas. Os materiais elaborados deixaram transparecer dificuldades convergentes quanto ao nível de aprofundamento dos aspectos históricos e epistemológicos, bem como quanto à formulação discursiva (OLIVEIRA; DRUMMOND 2015 p. 173).
\end{abstract}

A pesquisa desenvolvida no trabalho A08 tinha por objetivo compreender o desempenho de leituras de/sobre HFC na formação inicial do professor de física. Possuía como perguntas orientadoras para a coleta e informações e análise: "Como licenciandos em Física produzem significados ao lerem textos de/sobre HFC? Como eles situam a possibilidade de virem, ou não, a trabalhar com elementos HFC quando professores?".

Os principais aspectos no desenvolvimento do projeto foram: seleção de textos abordando a HFC; aplicação de um questionário inicial sobre suas percepções quanto ao uso da HFC no ensino; trabalho com os textos em sala de aula a partir de leituras em grupos, leituras individuais, discursões e exposição oral por parte do professor; elaborações escritas de análises e sínteses de textos; organização e participação em seminários; produção e solução de questões formuladas em avaliações escritas; elaboração de um artigo por cada participante; aula para socialização das percepções dos estudantes ao longo do curso; análise qualitativa do desenvolvimento do projeto e dos dados obtidos por meio das produções entregues e observações feitas.

Ainda sobre o trabalho A08, a análise do trabalho desenvolvido com as leituras mostra que a discussão em torno da implementação da HFC deve também pressupor discutir a importância e significação do que está sendo estudando:

\footnotetext{
Verificou-se grande diversidade, manifestada por esses licenciandos, com relação a posições que foram chamados a assumir ao responderem questões abertas. Essa diversidade mostra que a inclusão da HFC, nos currículos das licenciaturas, deve pressupor o trabalho com procedimentos que possibilitem a compreensão, ainda que parcial, de como os licenciandos adquirem conhecimentos, mas, também, das suas posições. Posições sobre a relevância ou não do que estão estudando, para pensarem
} 
seu futuro profissional - se e como incluirão os conhecimentos adquiridos nos seus planejamentos ALMEIDA. 2012 p. 40).

$\mathrm{O}$ artigo A05 e A09 trazem discursões sobre a importância da HFC para o ensino de ciências, constituem-se como revisões das concepções de autores e reflexões sobre o tema. Em ambos é possível encontrar aspectos históricos do desenvolvimento do ensino de ciências no Brasil e inserção da HFC, no entanto o A05 dá mais atenção para essa linha histórica do desenvolvimento do ensino de ciência no país.

Nos dois trabalhos as reflexões e discursões levantadas convergem para percepções positivas quanto à abordagem da temática no ensino, no artigo A05 pode se encontrar:

Dessa forma, por exemplo, uma unidade didática que apresente, no seu cerne, a HFC pode funcionar como uma boa saída para a constante desmotivação encontrada nas aulas de ciências. No Brasil, desde a criação dos $\mathrm{PCN}$, vários programas relacionados à educação científica tentam elaborar saídas para o pessimismo que aflora nas aulas de ciências. Nesse sentido, estratégias didáticas que envolvam a HFC podem ser mecanismos relevantes para apresentar aos alunos uma ciência mais viva e dinâmica (ATAIDE; SILVA 2011, p. 178).

O artigo A06 traz uma investigação sobre as percepções de licenciandos sobre a inserção da HFC no Ensino Médio. A investigação contou com a participação de 50 graduandos de vários cursos de Licenciatura em Física do Nordeste, a investigação se deu pela aplicação de um questionário com quatro questões abertas que visava analisar o interesse dos licenciandos pela HFC e mapear as principais dificuldades encontradas para a implantação desse tema no EM.

A pesquisa aconteceu durante a oferta de um minicurso sobre o tema no evento "Encontros de Físicos Norte e Nordeste". A avaliação dos resultados se deu por uma abordagem qualitativa e quantitativa, os resultados da pesquisa apontam para:

\section{[...] que quase todas as dificuldades de inserção da HFC no ensino Médio passam pela questão da formação do professor de Física. Este dado serve de alerta tanto para os formadores como para as instituições formadoras que algo está errado, e que os cursos e disciplinas relaciona- dos à HFC devem ser repensados, visando oferecer me- lhores subsídios aos futuros professores [SILVA 2011a $\mathrm{p}, 164)$.}

Quanto à questão consultando a opinião dos participantes sobre a inserção da HFC no Ensino Médio, obteve-se como resultado que 32 dos participantes, 64\%, eram favoráveis a essa inserção enquanto 18 participantes, $36 \%$, se mostravam não favoráveis. As impressões gerais trazidas pela pesquisa são:

\begin{abstract}
Embora os futuros professores de Física, como apontamos nessa pesquisa, não possuam uma fundamentação adequada relacionada a questões da HFC, discussões nesse sentido são realizadas desde a década de 80 do século, muito devido à consolidação da Didática das Ciências como corpo coeso e robusto de pesquisa.

Dessa forma, fica de lição para os professores formadores e para as instituições responsáveis pela formação desses professores, realizar discussões no intuito de angariar melhores resultados não só na formação do professor de Física de forma geral, mas, no que diz respeito à HFC [SILVA 2011a p. 165).
\end{abstract}

O trabalho A07 trata do desenvolvimento de uma pesquisa predominantemente qualitativa por meio de uma investigação documental que tinha como questão central "Como a História e Filosofia da Ciência está inserida na estrutura curricular dos cursos de Licenciatura em Física do estado de Minas Gerais?". Para tal o projeto teve como etapas para o seu desenvolvimento: a identificação das instituições de ensino superior que ofertavam cursos de Licenciatura em Física; coleta nos sites das instituições de documentos como Projeto Político Pedagógico (PPP)/Projeto Político Curricular (PPC), Grade/Estrutura Curricular e Ementas de disciplinas; organização dos do dados e analise.

No trabalho foram identificadas 23 instituições que ofertavam cursos de licenciatura em física, sendo 15 públicas e 08 privadas. Das públicas, 14 eram federais (11 universidades e 03 institutos) e 01 era estadual. O número de cursos identificados foram um total de 32 cursos, sendo 28 na modalidade presencial e 04 na modalidade a distância. A pesquisa identificou que 24 cursos apresentavam, em seus currículos, disciplinas com conteúdo histórico, filosófico e/ou epistemológico da ciência. No que tange as disciplinas foi constatado que:

\footnotetext{
Identificamos 24 cursos que apresentam, em seus currículos, disciplinas com conteúdo histórico, filosófico e/ou epistemológico da ciência. Essas disciplinas aparecem nos currículos com as seguintes denominações: "História da Ciência", "Evolução da Física", "Construção do conhecimento da Física", "Origem e Evolução das ideias da Física" e "Filosofia da Ciência".

Há casos em que uma disciplina trata apenas dos aspectos históricos enquanto que outras apenas dos aspectos filosóficos, como é possível observar pelos nomes dados às disciplinas. Por outro lado, um curso não apresenta nenhuma disciplina (LONDERO 2015 p. 25).
}

Outros aspectos importantes levantados na investigação foram o momento em que essas disciplinas eram ofertadas, qual a carga horária e quais os objetivos da disciplina que constavam nos documentos citados. As constatações obtidas pela pesquisa podem ser expressas nos seguintes recortes: 


\begin{abstract}
Os cursos, que inserem alguma disciplina, possuem diferentes objetivos, seja o de introduzir o pensamento científico, as posições e obstáculos da ciência moderna, analisar a história, a filosofia e a epistemologia do desenvolvimento dos conceitos da física, da antiguidade aos dias atuais, discutir o papel social e cultural da física na nossa era ou analisar as diversas concepções da ciência na história.

Não restam dúvidas de que alunos de licenciatura em física, futuros professores, devem possuir entendimento de conhecimentos acerca da natureza científica e uma compreensão conceitual da ciência. Perante isso, destacamos a necessidade de reflexões em relação aos momentos e tempos didáticos destinados às disciplinas que contemplam conteúdos históricos, filosóficos, sociológicos e epistemológicos da ciência (LONDERO 2015. p. 31).
\end{abstract}

De forma global, os principais pontos positivos alegados nos trabalhos para a inserção da HFC é que ela pode contribuir para: a aprendizagem significativa de conceitos e equações físicas; a desconstrução de visões distorcidas quanto à ciência e ao estereótipo do cientista; apresentar a ciência como algo de caráter evolutivo; inserir novas estratégias didáticas no ensino de ciências; como aspecto motivador frente ao preocupante quadro de desmotivação no ensino; facilitar abordagens interdisciplinares e contextualizadas de tópicos da ciência; entender a ciência como uma construção da cultura humana indissociável de aspectos, históricos, sociais e culturais, onde esta tanto influencia como é influenciada por eles; melhorar a formação do professor auxiliando o desenvolvimento de uma maior compreensão da estrutura das ciências; entre outros.

Os trabalhos também refletem e mapeiam os principais problemas e dificuldades em se inserir no ensino e trabalhar em sala de aula a Historia e Filosofia da Ciência, seja enquanto matéria (conteúdo) ou estratégias didáticas, entre eles/elas estão: baixa carga horária no ensino médio para se trabalhar HFC; pouca disponibilidade de materiais para se abordar a temática em sala; dificuldades de leitura por parte dos alunos, uma vez que boa parte das estratégias didáticas usam leituras de textos históricos; reprodução de práticas didáticas por parte dos docentes provenientes de suas formações sem a HFC; pouco espaço e valorização da HFC nos cursos de licenciaturas; entre outros.

\section{CONSIDERAÇÕES FINAIS}

Pela análise dos trabalhos é possível inferir que há um consenso quanto aos aspectos positivos do uso da HFC no ensino de ciências, alguns trabalhos citam essa convergência das pesquisas em didática em ensino de ciência e alguns orientam suas discussões a partir disso.
Também se observaram reflexões realistas quanto às limitações e dificuldades em se trabalhar e inserir a HFC no ensino seja no ensino básico ou superior. As conclusões dos artigos que trazem reflexões teóricas sobre o tema se confirmam quando confrontadas com as pesquisas que analisavam aplicações de estratégias didáticas em sala de aula, investigações sobre as percepções de docentes e licenciandos, e pesquisas documentais desenvolvidas em parte dos trabalhos.

A análise dos artigos demonstra que há uma variedade de abordagens quanto ao tema, as principais são: reflexões sobre a inserção e importância da HFC no ensino de ciência; investigações sobre as percepções de professores e alunos sobre o tema; analises documental de publicações na área e de documentos institucionais e aplicações de estratégias didáticas usando da HFC em sala. Algo relevante sobre as publicações é a predominância de trabalhos dentro da área da física.

\section{REFERÊNCIAS}

ALMEIDA, M. J. P. M. Leituras de história e filosofia da ciência na formação inicial de professores. Educação: teoria e prática, v. 22, n. 40, p. 26-42, 2012.

ATAIDE, M. C. E. S.; SILVA, B. V. d. C. As metodologias de ensino de ciências: contribuições da experimentação e da história e filosofia da ciência. HOLOS, Instituto Federal de Educação, Ciência e Tecnologia do Rio Grande do Norte, v. 4, n. 1, p. 171-181, 2011.

BARDIN, L. Análise de Conteúdo. 1. ed. São Paulo: Edições 70, 2011.

BEZERRA, E. V. L. Análise de propostas didáticas de história e filosofia da ciência para o ensino de física. Dissertação (Mestrado em Educação em Ciências e em Matemática) — Universidade Federal do Paraná, Curitiba, MG, 2014. 224 f.

BRASIL. Parâmetros curriculares nacionais: ensino médio. 1. ed. Brasília: Ministério da Educação, 1999.

LONDERO, L. A história e filosofia da ciência na formação de professores de física: controvérsias curriculares. História da Ciência e Ensino: construindo interfaces, v. 11, n. 1, p. 18-32, 2015.

MONTEIRO, M. M.; MARTINS, A. F. P. História da ciência na sala de aula: Uma sequência didática sobre o conceito de inércia. Caderno Brasileiro de Ensino de Física, v. 37, n. 4, p. 4501, 2015. 
MOURA, B. A. O que é natureza da ciência e qual sua relação com a história e filosofia da ciência. Revista

Brasileira de História da ciência, v. 7, n. 1, p. 32-46, 2014.

OLIVEIRA, W. C.; DRUMMOND, J. M. H. F.

Refletindo sobre desafios à inserção didática da história e filosofia da ciência em oficina de formação docente.

Alexandria: Revista de Educação em Ciência e Tecnologia, Universidade Federal de Santa Catarina (UFSC), v. 8, n. 3, p. 151-179, 2015.

PENITENTE, L. A. A.; CASTRO, R. M. A história e filosofia da ciência: contribuições para o ensino de ciências e para a formação de professores. Revista Eletrônica Pesquiseduca, v. 2, n. 4, p. 231-244, 2011.

RAPOSO, W. L. História e filosofia da ciência na licenciatura em física, uma proposta de ensino através da pedagogia de projetos. Caderno Brasileiro de Ensino de Física, v. 31, n. 3, p. 722-738, 2014.

RUTHERFORD, F. J.; HOLTON, G.; WATSON, F. Project Physics Course. 1. ed. New York, Toronto: Holt, Rinehart \& Winston, 1972.

SANTOS, F. M. Análise de conteúdo: a visão de laurence bardin. Revista Eletrônica de Educação, v. 6, n. 1 , p. $386-387,2012$.

SAUERWEIN, I. P. S.; DELIZOICOV, D. Formação continuada de professores de física do ensino médio: Concepções de formadores. Caderno Brasileiro de Ensino de Física, v. 25, n. 3, p. 439-477, 2008.

SILVA, B. V. C. Young fez, realmente, o experimento da fenda dupla? Latin-American Journal of Physics Education, Instituto Politécnico Nacional, v. 3, n. 2, p. $280-287,2009$.

SILVA, B. V. C. Controvérsias sobre a natureza da luz: uma aplicação didática. Dissertação (Mestrado em Ensino de Ciências Naturais e Matemática) Universidade Federal do Rio Grande do Norte, Natal, 2010.

A história e a filosofia da ciência no ensino médio: a visão dos futuros professores de física. HOLOS, v. 1, n. 1, p. 155-167, 2011.

História e filosofia da ciência como subsídio para elaborar estratégias didáticas em sala de aula: um relato de experiência em sala de aula. Revista Ciências \& Ideias ISSN: 2176-1477, v. 3, n. 2, p. 1 - 14, 2011. 